\title{
Estimation the Radioactive Pollution by Uranium in the Soil of Al-Kut City/ Iraq
}

\author{
Nidhala Hassan Kadhim* \\ Ryadh Younis Kassim* \\ Shurouq Jasim Jabbar*
}

Received 3, January, 2011

Accepted 20, May, 2011

\begin{abstract}
:
The aim of the present work, was measuring of uranium concentrations in 25 soil samples from five locations of Al-Kut city. The samples taken from different depths ranged from soil surface to $60 \mathrm{~cm}$ step $15 \mathrm{~cm}$, for this measurement of uranium concentrations. The most widely used technique SSNTDs was chosen to be the measurement technique. Results showed that the higher concentrations were in Hai Al- Kafaat which recorded $1.49 \pm 0.054 \mathrm{ppm}$. The uranium content in soil samples were less than permissible limit of UNSCEAR(11.7ppm).
\end{abstract}

Key words: uranium, Al-Kut, CR-39.

\section{Introduction :}

Natural radiation has always been part of the human environment. Its main components are cosmic and cosmogenic radiation, terrestrial gamma radiation from natural radionuclides in rocks and soil, and natural radioactive substances in our diet and in the air we breathe[1] .

Radionuclides are found in the environment as naturally occurring elements and as products or byproducts of nuclear technologies, one of the most common radionuclides is uranium (U), all isotopes of uranium are radioactive, so it is very important their quantity to be under control [2].

Nuclear fission in connection with atomic weapons testing and nuclear power generation provides some of the sources of soil contamination, the major part of radionuclides released into the environment will finally accumulate in either the upper layer of soils or interstitial system of sediments in aquatic systems[3].

Once the uranium is in the organism, it is transferred to the extracellular fluids and transported through the blood to other organs. Uranyl $\left(\mathrm{UO}_{2}{ }^{2+}\right)$ is the soluble form transported and it forms complexes with protein and anions. The risks related to exposure to uranium can be both chemical and radiological. The first is related to the binding of $U$ to biological molecules. This risk is particularly high for kidneys because of peak concentrations during the excretion[4].

\section{Materials and Methods:}

Al-Kut city is the center of Wassit one of the southern east Iraqi governorate which is laying between $\left(44^{\circ} 30\right.$ and $40^{\circ} 20^{\circ}$ ) longitude and ( $32^{\circ} 1^{\prime}$ and $33^{\circ}$ $\left.30^{\circ}\right)$ altitude ,the area of the city is about $\left(17153 \mathrm{~km}^{2}\right)$, it is far about $(180$ $\mathrm{km}$ ) from Baghdad city fig(1) [5].

*College of Science for Women-University of Baghdad/Department of Physics 




Fig (1) Location of Wassit governorate in Iraq



Fig (2) Samples locations in Al-Kut City

2. Solid State Nuclear Track Technique( CR-39)Detector
Solid state nuclear track detectors are insulating materials have the capabilities for measuring 
concentration and spatial distribution of isotopes if they emit heavy nuclear particles, either directly or as a result of specific nuclear reactions [6]. Operation of the solid-state nuclear track detector is based on the fact that a heavy charged particle will cause extensive ionization of the material when it passes through a medium. An alpha particle ionizes almost all molecules close to its path. Along the path of the alpha particle, a zone enriched with free chemical radicals and other chemical species is then created. This damaged zone is called a latent track. If a piece of material containing latent tracks is exposed to some chemically aggressive solution, chemical reactions would be more intensive along the latent tracks. Aqueous solutions of $\mathrm{NaOH}$ or $\mathrm{KOH}$ are the most frequently used chemical solutions in this regard. The overall effect is that the chemical solution etches the surface of the detector material, but with a faster rate in the damaged region. In this way, a "track" of the particle is formed figure (3), which may be seen under an optical microscope. This procedure is called "detector etching" or track visualization, and the effect itself is called the "track effect". However, only dielectric materials show the track effect. In conductive materials and in semiconductors, the process of recombination occurs and the latent tracks are not stable. One of the most commonly used nuclear track detectors is the CR-39 detector, which was discovered by artwright et al. is based on polyallyldiglycol carbonate. The basic physical processes after the initial charged particle loses its energy are the ionization and excitation of molecules of the material. This first "physical" phase in which the initial particle delivers its energy to the atoms surrounding its path is very short in time; stopping of the particle occurs within a time of the order of picoseconds. The free electrons created in these primary interactions will slow down through a series of ionizations and excitations, and will create more and more free electrons.. A large number of free electrons and damaged molecules are created close to the particle track. In the second physiochemical phase, new chemical species are created by interactions of the damaged molecules. During etching, the interactions of these new chemical species with the etching solution are stronger than that with the undamaged detector material. [7].
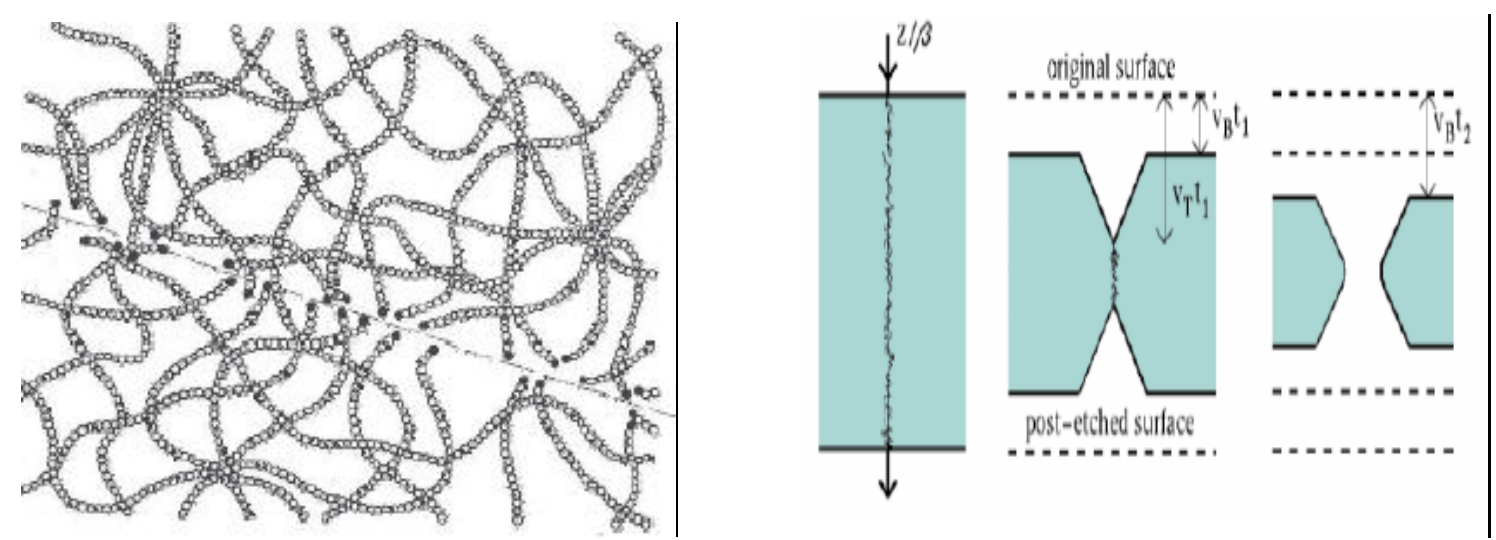

Fig(3). (left) The breaking of polymeric chains of plastic NTD(nuclear track detecter) by a crossing particle; (right) cross-view of the formation of the track after etching for two different times [8]. 


\section{Uranium Measurements}

soil samples were collected from the location of study (Al-Kut city) ,as shown in fig (2), the samples were taken for (5) depths $(0,15,30,45,60) \mathrm{cm}$. The samples were cleaned, dried at (100) ${ }^{\mathrm{O}} \mathrm{C}$ for 2 hours , milled and bolt, (0.5)g of the sample was mixed with $(0.1) \mathrm{g}$ of methylcellulose powder $\left(\mathrm{C}_{6} \mathrm{H}_{10} \mathrm{O}_{5}\right)$ as binding material .The mixture was pressed into a pellet with $(13 \mathrm{~mm})$ diameter and $(1.5 \mathrm{~mm})$ thickness. The pellets were covered with (CR-39) detector with area about $(1 \mathrm{x} 1) \mathrm{cm}^{2}$ and thickness $(1350 \mu \mathrm{m})$ and put in a plate of paraffin wax at a distance of $(5) \mathrm{cm}$ from the neutron source $(\mathrm{Am}-\mathrm{Be})$,with thermal neutron flux $\left(5 \times 10^{3}\right) \quad$ n.cm ${ }^{-2} \cdot \mathrm{s}^{-1}$. After the irradiation time (7 days) [9] CR-39 detector was etched in $6.25 \mathrm{~N}(\mathrm{NaOH})$ solution at temperature of $(60){ }^{\mathrm{O}} \mathrm{C}$ for (17)hours . The induced fission track density was recorded by using an optical microscope with $(400 X)$
.Uranium concentration in the soil samples was measured by comparison between track densities recorded on the detectors around the samples pellets and that of the standard geological sample pellets from the relation :

$\mathrm{C}_{\mathrm{x}} / \mathrm{C}_{\mathrm{s}}=\mathrm{T}_{\mathrm{x}} / \mathrm{T}_{\mathrm{s}}$

$\mathrm{C}_{\mathrm{x}}=\left(\mathrm{T}_{\mathrm{x}} / \mathrm{T}_{\mathrm{s}}\right) * \mathrm{C}_{\mathrm{s}}$

slope $=\mathrm{T}_{\mathrm{s}} / \mathrm{C}_{\mathrm{s}}$, where

$\mathrm{C}_{\mathrm{x}}$ :the uranium concentration in unknown sample

$\mathrm{C}_{\mathrm{S}}$ : the uranium concentration in standard sample

$\mathrm{T}_{\mathrm{x}}$ : Track density in unknown sample.

$\mathrm{T}_{\mathrm{S}}$ : Track density in standard sample.

fig (3) shows the relation between track density and uranium concentration (ppm) for standard geological samples using (CR-39) track detector.



Fig(3) the relation between track density and uranium concentration (ppm) for standard geological samples using (CR-39) track detector.[10]

\section{Resultas and Discussion :}

-Uranium concentration

Uranium concentrations were

ranged from $(1.491 \pm 0.054) \mathrm{ppm}$ in
Hai Al-Kafaat to $(0.744 \pm 0.049) \mathrm{ppm}$ in Hai Al-Anwar .Hai Al-Kafaat is the nearest to the city center which is effected by the bombardment of the 
last wars ,so as Hai-Al Rabee \& Hai Al-Ezaa, while both of Hai-Al-Askary \& Hai-Al-Anwar are less effected because the first is from the modern regions in the city and the other is laying in the other side from the city . The total average of uranium concentrations was $(1.255 \pm 0.0728) \mathrm{ppm}$, all the high concentrations were found at the soil surface as showing in Table(1), this is because that the radioactive content is laying on the surface of the soil and effecting by irrigation and rain fall the radioactive nucleus run away to the depths. The uranium content in soils samples are less than the allowed limit (11.7 ppm) from UNSCEAR[11],the little amount of uranium in the soil of Al- Kut city results from effecting the region by wars in the period from (1991-2003).

Table(1) Uranium concentrations in soil samples of Al-Kut city

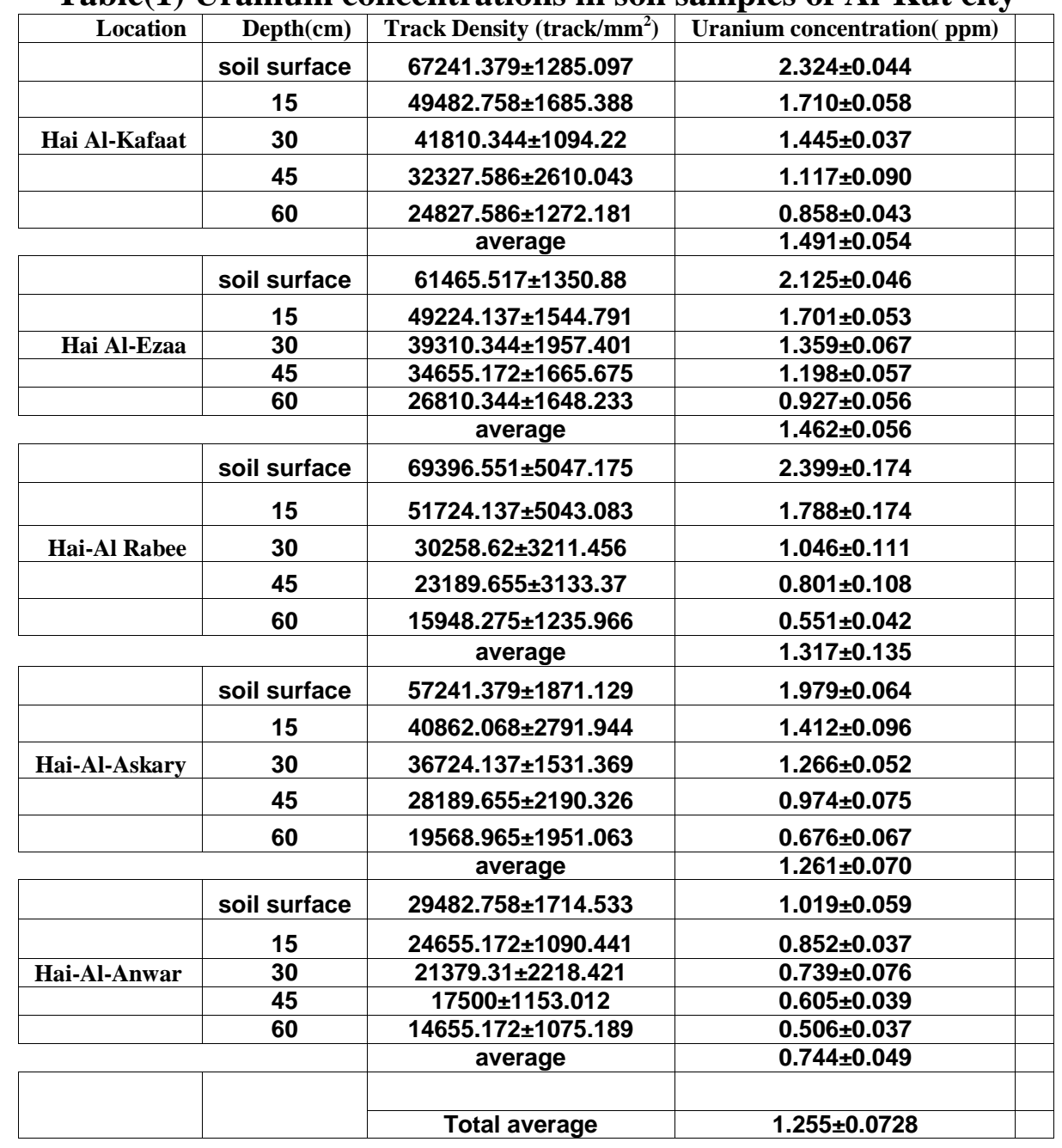

\section{Conclusion:}

From the results obtained in the present research, the following were concluded

1.The higher uranium concentration was in Hai Al-Kafaat.

2.The less uranium concentration was in Hai Al-Anwar.
3.The uranium concentration at the soil surface recorded the higher concentration than other depths.

4.All results obtained are less than the allowed limits by UNSCEAR .

\section{References :}

1. Bochicchio.F., McLaughling, J.P.and Piermattei. S., 1995" 
Radon in indoor air", European Collaborative Action(Report No 15),pp50.

2.Todorov, P. and Ilieva, E. N.; 2006," Contamination with uranium from natural and anthropological sources", Rom. Journ. Phys.,51(12) : 27-34.

3.Igwe, J.C; Nnorom,I.C.; and Gbaruko, B. C., 2005 " Kinetics of radionuclides and heavy metals behavior in soils : implications for plant growth " , Afr. J. Biotechnol. , 4 (13) : :1541-1547.

4. Busby,C. and Schnug,E. 2007" Advanced biochemical and biophysical aspects of uranium contamination" In, De Kok, L.J.ed"Loads and Fate of Fertilizer Derived Uranium", pp. $\mathrm{xx}-\mathrm{xx}$, Backhuys Publishers, Leiden, The Netherlands.

5. Jasem, A. A., 2007" Relationship Analysis Between Landuse And Urban Movement System Using G.I.S (Case Study Kut City)",M.Sc Thesis, the Higher Institute of Urban and Regional Planning, Baghdad University.

6. Hassan ,S. F., 2006"Determination of Uranium concentration in human blood samples in some governorate of Iraq by using CR-39 track detector" M. Sc. Thesis, Al-
Nahrain University, College of Science.

7. Nikezic ,D. \& Yu, K.N. 2004" Formation and growth of tracks in nuclear track materials", A review journal , Materials Science and Engineering, Report 46: 51-123

8. Fleischer R.L., Price P. B. and Walker R.M.,1975"Nuclear Tracks in Solids", Principle \& Applications, Univ. of California Press, Ltd.

9. Tawfiq, N.F. , 1996 "Study Comparssion in Some of Organic and Inorganic Track Detectors and Applications in Environment", Ph.D thesis, University of AlMustansiriyah, College of Education.

10. Al-Baidhani, M. A., 2006" Determination of the Radioactivity in Soil and Water in Baghdad, Karbala and Basrah Samples", M.Sc. Thesis, Al-Nahrain University, College of Science.

11. United Nations Scientific Committee on the Effects of Atomic Radiation, UNSCEAR,1993 "Sources, Effect, and Risks of Ionizing Radiation", Report to the general Assembly with Scientific Annexes, United Nations .

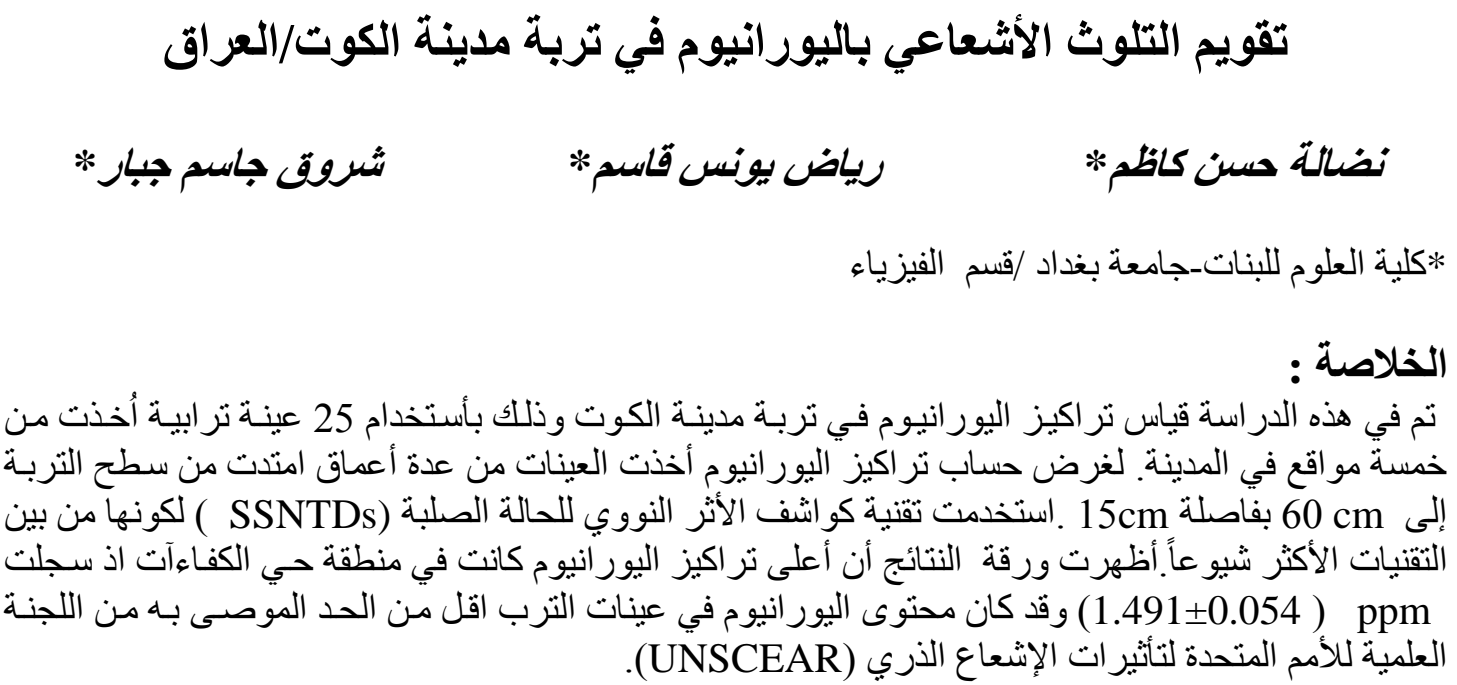

